\title{
Competence Assessment and Development for Managing Human Capital in the IT Sector
}

Vikram Singh Chouhan, Department of Humanities and Social Sciences, Jaypee University of Engineering and Technology, Guna (M.P.), India*

iD https://orcid.org/0000-0002-8643-2618

\begin{abstract}
With ever-increasing demand for software professionals, the time has come for the information technology (IT) industry to unearth competencies required for software professionals. The majority of IT companies have been employing outsourcing software projects to inexpensive hubs in developing nations. Therefore, expectations from highly skilled software professionals are rising. The purpose of the study is to recognize the technical competence levels associated with software professionals in a range of profiles which are found in India's major IT organizations. There are three basic objectives of the present study. The first objective is to conduct a literature survey of description of the software engineers in IT domain. The second objective is to quantify the competency levels of the software engineers in IT sector. Finally, the third objective is to conduct a survey-based empirical study on software engineers. The professional occupation is set up through seven successive profiles.
\end{abstract}

\section{KEYWORDS}

Competence Assessment, Competence Development, Competence Level, Human Capital, IT Sector, Software Engineers

\section{INTRODUCTION}

Human capital is the most essential asset comprising of the skill, dexterity and knowledge possessed by employees, necessary for achieving the goals of organizations (Guest, 2001; Becker \& Gerhart, 1996; Barney, 1991). It is also an area that needs a lot of improvement particularly in IT sector. The human resources are educated people and IT organizations require competent employees for achieving results proficiently, as IT organizations rely on the competence of the workforce for producing a ROI (return on investment) on the usage of technological and physical resources. Thus, human capital is the decisive contributor in determining organizational development nowadays. In addition, IT sector is confronted with the worldwide economic crisis, globalization, technological innovations and other changes. "Workforce characteristics and HR activities supply without a doubt the major source of opportunity for enhancing the productivity" (Boehm et al., 2000). Individual competence is needed to construct core competence of modern firms at organizational level (Bassellier et al., 2001). IT organizations need to systematically pursue competency management (Chouhan and Srivastava, 2013; 2014; 2015). 
The major factor influencing the software development process is competent software engineers with reference to software development teams (Pressman, 2005). Boehm states that "citizen factors have the most impact in shaping the endeavor needed to build up a software creation " (Boehm, 1981), and "Workforce characteristics and HR activities offer by a long way the biggest foundation of chance for enhancing IT development productivity" (Boehm et al., 2000).

Individual competency is needed in forming the core competency, vital for today's firms (Bassellier et al., 2001). Numerous studies have been done in IT field (e.g. Sackman et al., 1968) since 1960s. Prolific studies examining the importance of factors involving human capital in IT sector has surfaced after 1990s (Humphrey, 1998), and it is still increasingly growing from the outset of $21^{\text {st }}$ century (Tomayko \& Hazzan, 2004; Constantine, 2001; van Solingen et al., 2000). Chouhan and Srivastava $(2013 ; 2014 ; 2015)$ have recommended for conducting competence assessment and development for managing human capital in IT sector.

For improving the ability of the employees, numerous schemes, e.g., People-CMM (People Capability Maturity Model) (Curtis et al. 2001), elucidate a development plan commencing from improvised, erratically performed HR practices, and cultivate into a established practice infrastructure for constantly uplifting employee ability. According to People-CMM, level 3 means the area labeled as "Career Development", that executes the occupational career to make certain that employees are given chances to nurture their competencies which allow them to accomplish career goals. For achieving level 3, firms should decide about various occupational careers their workforce can assume, describing the occupational profiles and equivalent competence levels in a precise manner.

In addition, competence levels for occupational profiles are among the primary features regarding the development level of a profession, specifically "Professional Development". Software Engineering Body of Knowledge (SWEBOK) asserts the levels for all the elements of 10 knowledge fields (Abran et al., 2004). In line with Bloom's taxonomy, mentioned levels are decided on the basis of apprenticeship levels (Bloom, 1956). Nomenclature has been given for the sole profile having the qualification of Software Engineer having experience of 4 years. For complementing the ability levels set up by SWEBOK, supplementary competence explanation of ability levels for which 3 diverse Software Engineer's profiles must match up with dissimilar phases of occupational career: on completion of degree, post 4 years of experience, and as a experienced Software Engineer. However, this research might not be comprehensive, since knowledge fields are restricted to four: Quality, Maintenance, Processing, and Management (Bourque et al., 2004).

In addition, a number of attempts had been made to propose the skills and knowledge needed by software engineers in IT industry (Lethbridge, 2000; Turley \& Bieman, 1995), the course of software engineering (Kitchenham et al., 2005) and regular teaching of software engineers (Callahan $\&$ Perdigo, 2002). Further researches have been done concerning the competence required on behalf of information systems professionals (Wu et al., 2007); as IT project managers (Sukhoo et al., 2005); beginner software engineers (McMurtrey et al., 2008); chief information officers (Bassellier et al., 2001); as analysts (Misic \& Graf, 2004); and generally software engineers (Kovacs et al. 2006) to quote few major exemplar.

Above mentioned programs are hard to be put into practice by HR professionals, since they are restricted—as each sector's occupational profiles are not covered—or they are broad also, or explicitly precise to several fields of HRM (Acuña \& Juristo, 2004); pointing towards a range of knowledge exclusively connected to a software engineer profile. Recognizing competencies and ability for software engineers is an old field.

The current paper presents a research on the role of software professionals in the IT industry, in order to compile a "competency model". The theme has received increasing attention both from practice and theory (e.g. Gabryk \& Naidoo, 2020; Leidig et al., 2020; Topi et al., 2017; Impagliazzo et al., 2016). Taking vital cues from these studies, the current study recognizes an occupational career for SE, characterized with the help of the needed competence levels for all IT occupation for an explicit kind of firms of vital magnitude in the IT occupation, along with a specific geographic 
region. Particularly, the research has been derived from job profiles recognized in real firms: big consultancies as well as IT development firms. For defining the occupational career representation as completely as possible, a few combinations were left out from the study, such as specialty and twin career paths (managerial and technical).

The aforementioned discussion is sufficient to generate a plan of occupational careers for software professionals. The resurgence in global demand for IT workers leads to an important question: What competencies are important to transform the new millennium software professionals? This research addresses this question by borrowing general systems theory. Accordingly, following research objectives have been formulated:

1. To precisely define the occupational careers.

2. To set up an occupational career along with professional profiles, in addition to analysis of suitable career graphs designed for the firms.

3. To describe the competence scales of recognized profiles according to knowledge fields proposed by SWEBOK (Abran et al., 2004).

4. To define competencies associated with job profiles based on an empirical study.

To highlight the research objectives, the following conceptual diagram is proposed as shown in figure 1.

Figure 1.

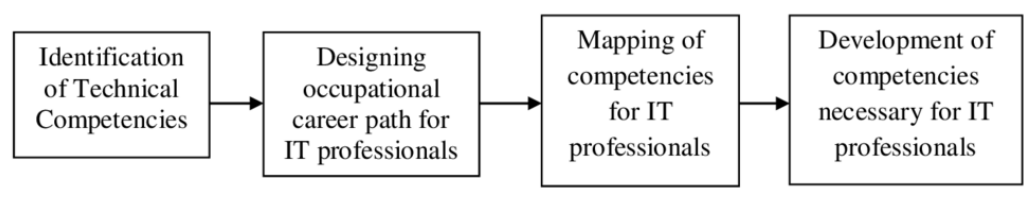

\section{LITERATURE REVIEW}

\subsection{An Occupational Career Path for IT Professionals}

In 2008, Association for Computing Machinery (ACM) and the IEEE Computer Society (IEEE$\mathrm{CS}$ ) published the first model curriculum report for undergraduate degree programs in information technology (IT), called IT2008 (Lunt et al., 2008). Since that time, many new technologies emerged and flourished. In 2012- 2013, ACM formed an exploratory committee to determine whether IT2008 required updating. After an affirmative response, ACM/IEEE-CS formed a task group charged with developing an update to IT2008 that was appropriately forward looking for IT graduates in the mid-2020s. The report, tagged IT2017, would encompass technology and educational advances that occurred since 2008 (Sabin et al., 2015). The IT2017 task group plans to produce a competency model and curricular guidelines for worldwide four-year IT degree programs that prepare graduates professionally for current and new technologies for the next decade.

The Information Systems (IS) 2010 report is also the output from model curriculum work for IS that began in the early 1970s (Topi et al., 2010). Prior to this effort, the most recent version of the IS undergraduate model curriculum is IS 2002 (Gorgone et al., 2003), published in early 2003. IS 2002 was a relatively minor update of IS '97 (Davis et al., 1997). Both IS 2002 and IS ' 97 were joint efforts by ACM, AIS, and DPMA/AITP (Data Processing Management Association/Association of 
Information Technology Professionals). In addition to IS 2010, curriculum recommendations exist for computer science (CS 2008), computer engineering (CE 2004), software engineering (SE 2004), and information technology (IT 2008).

Master of Science in Information Systems (MSIS) 2016 (Topi et al., 2017) is a competency specification for master's level degree programs in information systems (IS). It builds on the essential foundation of four earlier graduate IS model curricula (Ashenhurst, 1972; Nunamaker et al., 1982; Gorgone et al., 2000; Gorgone et al., 2006). At the same time, it represents in several ways a departure from them. Instead of prescribing a curriculum course model, this document specifies a set of Master of Science in Information Systems (MSIS) graduate competency requirements.

Cano et al. (2013) conducted a study on how the CIO (Chief Information Officer) position plays the main role in the firms and the requirements for candidates. This study compared the requirements mentioned in previous research works to determine the most important skills for a successful performance as a CIO. They stress the importance of non technical skills as key factors for professional performance. The study focused on comparing soft skills for CIO or equivalent positions and other professional profiles like programmers or analysts using data taken from thousands of job ads. In a separate research, a model was developed for cyber ethics and professional responsibility in computing (Alhassan et al., 2020).

Lee (2001) has suggested the scarcity in literature concerning definitions of occupational careers in IT domain. Numerous researches demonstrate the suggestibility of making the occupation accountable for the setting up of occupational career (Chesebrough \& Davis, 1983). Nevertheless, important programs like People-CMM (Curtis et al., 2001) revealed the significance of setting up an occupational arrangement for careers which are fixed, recognized and planned by the firm. This section presents an occupational career path that is defined and applied to those IT professionals who build up their careers in big consulting firms and software development corporations in India. For accomplishing this objective, an investigation will be conducted on three diverse aspects. All aspects add to the description of software engineer's occupational profiles within the IT industry. The resulting definitions will be used to propose a occupational career, anchored in subsequent research foundations:

- Global and local suggestions of occupational profiles for IT professionals.

- Research on what functions are performed by IT professionals in different kinds of organizations

- Occupational careers prevalent in organizations equivalent to the profile.

\subsection{Technical Competence}

Technical competence describes the application of knowledge and skills needed to perform effectively in a specific job or group of jobs within the organization. These types of competencies are closely aligned with the knowledge and skills or "know-how" needed for successful performance. In the context of IT sector, technical competence can be defined as how well IT professionals can apply IT knowledge, applications, and information systems to their tasks in an organizational computing environment (Yoon, 2009). In essence, the technical competencies are antecedents to improved performance (Marcolin et al., 2000).

There are several models within the appropriate software engineers literature: People- CMM (Curtis et al., 2001), SWEBOK (Abran et al., 2004), and most importantly Information Technology (IT) Competency Model (United States Department of Labor, 2012).

A broad competency model for the IT industry has been proposed by Employment and Training Administration (ETA) (United States Department of Labor, 2012). This IT Competency Model of The Employment and Training Administration recognizes the knowledge and skills required for employees to perform efficiently in information technology (IT) sector. The model is illustrated in the form of the pyramid encompassing numerous layers. Array of the layers on the contour is neither destined to be hierarchical, nor it means that competence on the peak of the pyramid require 
high skill-level. Rather, the model's shape symbolizes the growing specialty and explicit nature of skills covered. Its tiers are classified into chunks that embody competence region, that are described by vital job occupation and technical substance fields. It is not projected that software engineers acquire each competency listed. The model is a competency group that can be incorporated based on preparation in an IT software engineering role. Tier 4 of IT competency model (United States Department of Labor, 2012) provides technical competencies which are broadly applicable in IT industry: Basics of IT; telecommunication; databases \& applications; wireless \& mobility; networks; user $\&$ customer support, software development \& management; compliance; \& risk management, security, \& information assurance.

During last 3 decades, a lot of non-IT firms have deployed competence modeling to tactically manage organizational culture and practices (Vakola et al., 2007). Numerous Fortune 500 firms employ role-specific competency models for managing and leading their workforce (Boyatzis et al., 1996). Various professional segments build up their specific competence models. Clearly, the competence models developed for other sectors may not be perfectly valid to information technology sector. Nevertheless, there are numerous broad models appropriate in the IT sector, such as the Iceberg Model of Competencies (Spencer and Spencer, 1993), Hudson 5+1 Competence Model, and Boyatzis' General Model of Competencies (Boyatzis, 1982).

Hudson, a consulting company, proposed 5+1 Competency Model. It has got 5 competence clusters: people management, information management, interpersonal management, personal management, and task management. In addition, a sixth cluster for technical competence has been created. There are six clusters in Boyatzis' general model: human resource management, directing subordinates, leadership, goal and action management, specialized knowledge and focusing on others. A series of studies was performed by Boyatzis (1982) for scrutinizing the importance of skills and knowledge along with social roles in every cluster. Both models focus not on any specific job role, rather both models highlight social interaction skills along with managerial skills. Basically the clusters and competencies usually aim to train an employee to become a competent professional. On the contrary, Iceberg competency model does not centre around managerial jobs. Spencer and Spencer (1993) proposed 5 kinds of characteristics of competencies: skills, knowledge, self-concept, traits, and motives. Iceberg competency model offers a superior construal of a variety of competency groupings. It stresses that it is hard for a firm to distinguish if a person has 5 competencies, and that a number of characteristics are complicated to obtain. Numerous competencies are easy to own, whereas quite a few are taxing to cultivate. The competencies at the bottom of the triangle are concealed and hard to develop. As per Iceberg competency model, skills and knowledge are apparent and comparatively show characteristics of a person, while motives and traits are profound and reveal innermost personality. Self-concept characteristics occupy a level between them. Latent competency is the behavioral competency, while noticeable competency is the technical competency (Spencer and Spencer, 1993).

IT sector has been using People-CMM as one of the strong tool for enhancing the skills of the employees (Curtis et al., 2001). It presents a remarkable development lane which commences from informal and erratic HR practices and matures into an infrastructure to constantly raise employee skills. Proposed People-CMM has a level 3,"Defined" which means "Career Development", that applies the occupational career for making sure that each employee is given enough chances to expand the competence level which facilitates accomplishment of their career goals. For accomplishing level 3, organizations must find out various occupational careers their workforce may embark on, indicating in an overt manner the occupational profiles along with equivalent competence levels.

People-CMM's field "Development of Professional Careers" aims to describe occupational profiles, corresponding competence as well as necessities of occupational career build up (Curtis et al., 2001). The portrayal of occupational career is revealed in Figure II. This study presents an illustration of steady occupational chances, together with technical competence development within software engineering. The PCMM comprises of 5 maturity levels that set consecutive base for constantly enhancing capability, developing effectual technique, and productively leading the human capital of 
the firm. All maturity levels are developing areas that establishes a level of competency for nurturing the human capital within the firm.

Figure 2.

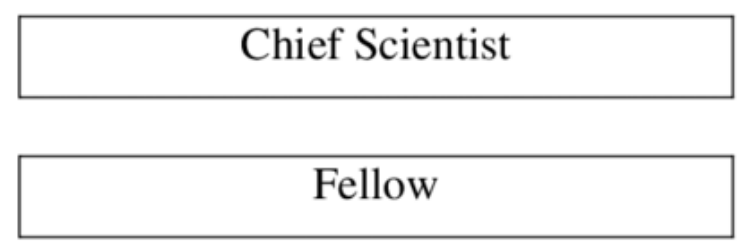

Sr. Consulting Software Engineer

Software System Architect

Software team leader

Senior Software Engineer

Software engineer

Software Programmer

The plan launches an occupational career, commencing with mostly technical profession, dividing into software team leader which afterward progress within the firm, depending on the enhancement of technical competence.

Lastly, the proposal for occupational development made by SWEBOK's (Abran et al 2004) covers 10 knowledge fields. The SWEBOK guide is produced, developed, and revised by important subject matter specialist internationally. SWEBOK is commonly acknowledged and practiced in India by both academic world as well as industry. Several colleges and universities have implemented SWEBOK and combined educational content into their software engineering program. The acceptance of SWEBOK at colleges and universities assists to train the students for the software industry.

\subsection{Practices in Indian IT Industry}

Indian IT sector has put India on the international map. The Indian IT industry has achieved brand recognition in the form of a knowledge economy because of its IT industry. Nowadays IT industry leads the financial development. The Information technology sector is offering employment to about 14 
million people in 2020. Indian IT firm such as Wipro, HCL, TCS, and Infosys have become household names across the globe. Numerous Indian IT firms are keen to know the current level of competence of human capital with the intention that sufficient actions might be planned to enhance their performance. Therefore, focal point of this study should be competence mapping of IT professionals in Indian IT sector. Consequently, one of the objectives of this research is to investigate the competencies that impact performance of IT professionals.

Organizations across the globe are witnessing competency scarcity that is pondering on development outlook (India Skills Report, 2014). Approximately 39\% organizations across the globe are besieged to hire the competent workforce and chief concern (63\%) being deficiency of technical competency. The other challenges are scarcity of universal employability abilities like cooperation, communications and others (India Skills Report, 2014).

Indian IT sector is challenged by issues such as attrition, employee loyalty, confidentiality, etc. Rising attrition rate would take the operational cost to increased levels, along with low productivity and the firm will fritter away edge to its competitors (Harvard Management Update, 1999). The HR professionals nowadays are http://doing manifold functions than what they have done in the past (Dasari, 2008). Brain-drain from leading technical institutions, such as the IITs, has been a cause of distress to Indian IT sector. In addition, the premier institutions have been questioned for not churning competent software engineers to meet the demands of the Indian software industry. Thus, sluggish yield of engineering institutions absolutely add to the software engineers scarcity in Indian IT sector.

Practices in Indian IT Industry is examined on the basis of professional career exams employed by three major IT organizations in India, to be called A, B and C for the present study. Organization $\mathrm{X}$ is an Indian software firm which employs 8000 workers. Being a large firm, it has diverse positions, nevertheless, only positions appropriate to IT engineers has been included in this study. This organization comprises of these functions in descending succession: Director, Expert Mastery, Technician I, Technician II, Technician III, and Technician IV.

Organization $\mathrm{Y}$ is an Indian software firm which employs 15000 workers. This organization comprises of these functions in descending succession: partner, general manager, project manager, systems analyst, application analyst, application programmer, IT encoder.

Lastly, organization $\mathrm{Z}$ is an Indian software firm which employs 20000 workers. It has numerous distinct profiles for occupational careers associated with IT, which are in hierarchical order: director, business manager, project manager, functional analyst, organic analyst, and programmer.

The paper aims to assess the perceived technical competence levels of software engineers in India and it provides an empirical evaluation of how these competencies impact the performance of software and its consequent influence on HR practices. It is described by means of quantifying current level of competence of the workforce with the intention that appropriate initiatives might be used to enhance their performance. This calls for competency mapping through proper HRM initiatives. Specially, the research is carried out according to job profiles recognized in IT organizations in India: software firms and big consultancies.

\subsection{Scheme for Occupational Career}

The theoretical approach to cover is the general systems theory (von Bertalanffy, 1968) because it helps to structure the career and to ensure sufficient coverage of basic understanding that an occupational career constitutes not only technologies and software but also a whole system with users and their activities. Systems theory is also a helpful viewpoint into the complexities in all competency areas.

The investigation of prominent occupational profiles recognized in the resource foundation as stated earlier produces the definition of an occupational career which is appropriate according to kind of software development firms and consulting firms mentioned previously. Proposed occupational career is the consequence of a resemblance analysis among each reference conferred with. A study has been performed to take out resemblance among descriptions for all occupational profile in each 
resource foundation. The outcome of this study and the association among profiles is displayed in Table I.

Table 1. Scheme for occupational profiles for software engineers

\begin{tabular}{|c|c|c|c|c|c|}
\hline & \multicolumn{2}{|c|}{ Literature } & \multicolumn{3}{c|}{ Organizations } \\
\hline Scheme & $\begin{array}{c}\text { Information Technology } \\
\text { Competency Model }\end{array}$ & People CMM & $\mathrm{X}$ & $\mathrm{Y}$ & $\mathrm{Z}$ \\
\hline A & Director & Division & Director & Partner & \\
\hline & & Manager & & & \\
\hline & & Vice-President & & & \\
\hline B & & Program & IT Mastery & General & General \\
\hline C & Mroject & Manager & & Manager & Manager \\
\hline & Manager & Project & IT Expert & Project & Project \\
\hline D & & Senior SW & IT Technician & Manager & Manager \\
\hline & & Engineer & IV & System & Functional \\
\hline E & & SW Engineer & $\begin{array}{c}\text { IT Technician } \\
\text { III }\end{array}$ & Application & Organic \\
\hline & & & & Analyst & Analyst \\
\hline F & & Support & IT Technician \\
II & Application & Programmer \\
\hline G & & Programmer & & Programmer & \\
\hline
\end{tabular}

\section{RESEARCH METHODOLOGY}

This research is done to describe the extent of technical competence for the established profiles for software engineers, needed for all the occupational profiles. The definition of technical competence within this research, from an occupational viewpoint was deemed to be an extremely important factor. Competence researches for IT professionals (Turley \& Bieman, 1995) do not demonstrate competence levels, and center merely on the possession of competencies obvious to professionals which are pertinent for effective job performance. Nevertheless, all through the definition of those competence profiles, discrete occupational profiles were excluded, because these studies were quite old. Hence, progression of the occupation or changes in needs because of the surfacing of novel prototype and fresh technologies has been omitted. Knowing this present standing, it was considered elementary to conduct a research that examines the views of software engineers working in the IT firms nowadays. This empirical research is done to help prepare the scheme for competence levels in the occupational profiles described earlier. The purpose is to institute the professionals' viewpoint on technical competence levels for all occupational roles recognized. The comprehensive set of competencies match up to the 10 knowledge fields proposed by SWEBOK (Abran et al., 2004). A questionnaire was designed to define competencies for the software engineers profiles defined earlier. 
A 7-point Likert scale ranging from 1 to 7 points was employed. The depiction of the scale will be common for each competency, displaying the subsequent arrangement of values from $1=$ very low level to $7=$ very high level.

The data was collected from a sample of 456 software engineers functioning in IT field in India. Presuming that the software engineers had the appropriate experience of working in the industry, they were interviewed before their actual interview for the purpose of validating their comprehension of the IT field, with establishing whether their understanding was ample for the purpose of the research. The respondents' demographics include following information: The mean age of respondents was 33.8 years, with a mean work experience of 9.27 years. Male respondents were $261(57 \%)$ and female respondents were $195(43 \%)$. The allocation of the respondents across the groups recognized earlier was consequently set up, on the basis of the interviews:

\section{RESEARCH FINDINGS}

The mean scores (M), standard deviations (SD) and modes (Md) of software engineer's technical competencies are displayed in table II for the diverse profiles recognized.

The descriptive statistics do not elucidate the goals of the research adequately. Hence, further analysis was conducted for addressing the appropriate research questions framed for this study.

For determining the most significant technical competency for all occupational profiles, Table III displays a contrast of means and modes for all technical competencies. Considering the whole mean, Software Design is found to be the most important competency, followed by Software Engineering Management. The competency which is found to be the least important is Software Maintenance, followed by Software Construction. Nevertheless, it is imperative to mention that these numbers of competencies are very close to each other, and there is no major disparity between technical competencies.

For determining the comparative significance of software engineer's technical competencies, means and modes of technical competencies for each occupational profile were analyzed. "C" demonstrates the maximum technical competence, afterward " $E$ " and " $D$ ".

The institution of a firm's competence levels is deemed by People-CMM as an element of a professional development plan. People-CMM particularly reveals the obligation for a software engineer to be acquainted with the competencies he requires for future levels in his career. To achieve this objective, competence levels—recognized as important differences among scores of technical competencies in associated profiles - were computed by contrasting means through T-test for associated samples. For each technical competency comparisons were made 2 by 2 , to locate important differences which will rationalize the potential addition, through negative T's, or reduction of competencies among associated profiles. The findings exhibit that important addition in each technical competencies are apparent among categories $\mathrm{F}$ and $\mathrm{G}$, an analogous sample being observable in the change among $\mathrm{E}$ and $\mathrm{F}$. To distinguish between $\mathrm{D}$ and $\mathrm{E}$, important addition in each competencies was created, apart from the competency "Software Construction", with the value $\mathrm{t}(455)=5,759, \mathrm{p}<.05$. Investigating C, important addition in "Software Engineering Process" $\mathrm{t}(455)=-$ 4,683, $\mathrm{p}<.05$ and "Software Engineering Management" $\mathrm{t}(455)=-6,961, \mathrm{p}<.05$, were apparent, whereas a important reduction might be observed in the competencies deemed further related with Software Development, i.e., "Software Construction", "Software Requirements", "Software Design", "Software Maintenance", and Software Testing".

Competence level needed for every knowledge field and software engineers' occupational profile within different kind of firms were analyzed. Competence values have been assigned as per the scores awarded by the experimental subjects, mirroring competence needs for diverse occupational profiles. As mentioned in a Likert scale ranging from 1 - 7, scores were originally allocated through rounding off the mean scores for diverse occupational profiles. Consequently, they were developed as 
Table 2. Mean scores, modes and standard deviations of occupational profiles

\begin{tabular}{|c|c|c|c|c|c|c|c|c|c|c|c|}
\hline \multicolumn{2}{|c|}{ Competencies } & $\begin{array}{c}\text { Software } \\
\text { Requirements }\end{array}$ & $\begin{array}{l}\text { Software } \\
\text { Design }\end{array}$ & $\begin{array}{c}\text { Software } \\
\text { Construction }\end{array}$ & $\begin{array}{c}\text { Software } \\
\text { Testing }\end{array}$ & $\begin{array}{c}\text { Software } \\
\text { Maintenance }\end{array}$ & $\begin{array}{c}\text { Software } \\
\text { Configuration } \\
\text { Management }\end{array}$ & $\begin{array}{l}\text { Software } \\
\text { Quality }\end{array}$ & $\begin{array}{c}\text { Software } \\
\text { Engineering } \\
\text { Management }\end{array}$ & $\begin{array}{c}\text { Software } \\
\text { Engineering } \\
\text { Tools and } \\
\text { Methods }\end{array}$ & $\begin{array}{l}\text { Software } \\
\text { Engineering } \\
\text { Process }\end{array}$ \\
\hline \multirow{3}{*}{ A } & $\mathbf{M}$ & 1.89 & 1.46 & 1.43 & 1.26 & 1.21 & 1.5 & 1.69 & 2.69 & 1.85 & 2.6 \\
\hline & SD & 0.62 & 0.951 & 0.521 & 0.478 & 0.662 & 0.74 & 0.899 & 1.36 & 0.676 & 1.23 \\
\hline & Md. & 4 & 2 & 1 & 2 & 1 & 1 & 1 & 1 & 1 & 1 \\
\hline \multirow{3}{*}{ B } & M & 2.91 & 1.59 & 1.84 & 1.56 & 1.98 & 2.54 & 2.43 & 3.72 & 2.56 & 2.49 \\
\hline & SD & 0.801 & 0.721 & 0.823 & 0.701 & 0.952 & 1.931 & 1.79 & 0.81 & 0.79 & 0.681 \\
\hline & Md. & 3 & 4 & 2 & 1 & 1 & 1 & 2 & 1 & 1 & 2 \\
\hline \multirow{3}{*}{ C } & M & 3.56 & 2.16 & 2.59 & 2.89 & 2.71 & 3.59 & 3.9 & 3.73 & 3.82 & 3.69 \\
\hline & SD & 0.894 & 0.897 & 0.701 & 0.862 & 0.873 & 0.95 & 0.74 & 0.62 & 0.742 & 0.591 \\
\hline & Md. & 4 & 3 & 4 & 3 & 4 & 3 & 4 & 2 & 4 & 3 \\
\hline \multirow{3}{*}{ D } & M & 3.84 & 3.81 & 3.73 & 3.89 & 3.45 & 3.56 & 3.94 & 2.43 & 3.79 & 3.81 \\
\hline & SD & 0.61 & 0.684 & 0.502 & 0.643 & 0.406 & 0.59 & 0.539 & 0.785 & 0.398 & 0.689 \\
\hline & Md. & 4 & 3 & 4 & 3 & 4 & 4 & 4 & 4 & 4 & 4 \\
\hline \multirow{3}{*}{$\mathbf{E}$} & M & 2.59 & 3.4 & 3.98 & 3.47 & 3.59 & 3.73 & 3.49 & 2.81 & 3.79 & 2.84 \\
\hline & SD & 0.81 & 0.51 & 0.89 & 0.578 & 0.891 & 0.659 & 0.64 & 0.889 & 0.779 & 0.851 \\
\hline & Md. & 3 & 4 & 4 & 3 & 3 & 4 & 3 & 3 & 3 & 4 \\
\hline \multirow{3}{*}{$\mathbf{F}$} & M & 1.72 & 2.59 & 3.64 & 3.91 & 4.69 & 2.98 & 2.19 & 2.79 & 3.41 & 2.74 \\
\hline & SD & 0.92 & 0.803 & 0.798 & 0.846 & 0.902 & 0.879 & 0.899 & 0.667 & 0.736 & 0.785 \\
\hline & Md. & 1 & 4 & 1 & 2 & 4 & 1 & 2 & 4 & 2 & 2 \\
\hline \multirow{3}{*}{ G } & M & 1.84 & 1.32 & 2.12 & 2.95 & 2.84 & 1.79 & 1.45 & 1.64 & 1.91 & 1.89 \\
\hline & SD & 0.682 & 0.697 & 0.946 & 0.983 & 0.919 & 0.635 & 0.648 & 0.467 & 0.725 & 0.596 \\
\hline & Md. & 1 & 2 & 2 & 1 & 2 & 2 & 1 & 1 & 1 & 2 \\
\hline
\end{tabular}

Table 3. Competence level per profile

\begin{tabular}{|l|c|c|c|c|c|c|c|}
\hline \multicolumn{1}{|c|}{ Competency } & A & B & C & D & E & F & G \\
\hline Software Quality & 2 & 2 & 7 & 6 & 7 & 6 & 6 \\
\hline Software Engineering Process & 2 & 4 & 7 & 7 & 6 & 4 & 4 \\
\hline Software Requirements & 6 & 2 & 6 & 4 & 7 & 6 & 4 \\
\hline Software Testing & 2 & 4 & 7 & 6 & 7 & 4 & 4 \\
\hline Software Maintenance & 1 & 7 & 6 & 6 & 6 & 4 & 2 \\
\hline Software Configuration Management & 2 & 4 & 7 & 6 & 7 & 4 & 4 \\
\hline Software Engineering Management & 3 & 6 & 7 & 7 & 6 & 4 & 4 \\
\hline Software Engineering Tools and Methods & 2 & 6 & 7 & 7 & 6 & 4 & 2 \\
\hline Software Design & 4 & 4 & 7 & 7 & 6 & 7 & 3 \\
\hline Software Construction & 2 & 2 & 7 & 6 & 6 & 6 & 4 \\
\hline
\end{tabular}


per competence scales which were described earlier, to eventually set up the progression of software engineers competencies within IT environment.

Therefore, the earlier explanation of occupational profiles can be finished by appending the related competence levels summarized and explained below:

A: Engineers within this group do not emphasize on technical competencies related to software engineer because of assurance to Management and the Software Process.

B: This profile reveals high level of management skills and Software Maintenance. Employees within this category possess intermediate levels.

C: Engineers within this category possess top level of technical competencies. They are extremely competent in Software Quality, Engineering Process, Testing, Configuration Management, Engineering Management, Engineering Tools and Methods, and Design. They also possess a top level of competence of management and software construction.

D: Engineers within this category demonstrate extremely top level of competence on Software Engineering Process, Software Engineering Management, Software Engineering Tools and Methods, and Software Design, and have low competence level on requirements.

E: Engineers within this category were found to possess a deep knowledge of Software Quality, Software Requirements, and Software testing besides having a top level of competence of other software engineer's technical competencies.

F: Engineers within this category were found to be possessing high level of competence in Software Design, Software Quality, and Software Requirements. Engineers within this category were found to have an intermediate level of competence in other technical competencies.

G: This category reported a high competence level regarding Software Quality, with lowest level of competence attached to Software Maintenance.

The most important confirmation of the study is the pyramidal structure of software engineer professional careers in the selected firms. The pinnacle of the pyramid is characterized by profile "C", illustrating the top most level of technical competency. This attribute verifies the software engineer's perception of smaller significance of technical competence in top profiles compared to middle profiles, as opposed to the incorporation and sustained competence development stated by Construx (McConnell, 2003) except in the same career path demonstrated by Lannes (2001) in a archetypal engineering career path.

\section{DISCUSSION AND IMPLICATIONS}

The endeavor of this research was to comprehend how different competency models can be analyzed to examine the technical competencies needed for software professionals and to embark its implications for industry hiring and university education.

\subsection{Theoretical Implications}

This research is the latest addition to the software professional's literature. Job analysis has been used by Government and industrial institutions for illustrating the demands of the job, but it is task-specific and center just on knowledge \& skills. For instance, database $\mathrm{O} *$ Net employs over two hundred and fifty descriptors for all nine hundred odd occupations. A competency framework helps HR professionals in making a job description, but it does not succeed in substantiating the significance of latent attributes of the workforce for efficiently carrying out tasks of their firms. For addressing this gap in literature, we update competency modeling with this research. With a range of appearance and flexibility, this research recognizes the competencies that need to be cultivated in the classroom through education. 
The process of identifying can act as the base for additional thorough investigation concerning the role of software professionals or project managers.

Competency modeling offer software professionals and human resource professionals a universal vocabulary to converse personnel matters. Conversely, it is sensible to consider that competency modeling is not the solitary answer for each industry hiring (Cockerill et al., 1995). Likewise competency modeling is not the lone method used in university education (Dalton, 1997). Outlining competencies as a result might neglect the individual and intellectual processes that emphasize knowledge \& skills (Ashworth and Saxton, 1990). Several peculiar competencies which might assist an employee to succeed in their job, or give a competitive edge to a company, might be overlooked if the competency modeling is employed exclusively to tactically pick merely a workforce that fit the model.

\subsection{Practical Implications}

The main practical contribution of the current research is to answer a present-day software professional question using the competency modeling - which competencies are essential to modern workforce? The software sector in developed nations is changed as software projects are outsourced to economical hubs in developing nations and the corresponding increase in demand for high-level IT competencies at home. This tendency is only going to be augmented, thereby drastically altering the nature of the software professionals. As contemporary software professionals scale their profession ladders, they are anticipated to acquire numerous non-IT competencies. Therefore, Software Engineering educational institutions necessitate updating their courses to counterpart industry requirements. Technical courses, like systems analysis and design, and database management stay as an integral part of any Software Engineering program, simultaneously a bit managerial component should also be included. University Programs must be centered on nurturing significant, noticeable and simple to develop competencies.

During the design of programs, it is imperative to identify that a number of knowledge or skills are universal and helpful to Software Engineering roles, however several knowledge or skills are more dedicated for Software Engineers only. The program design must designate an obvious lane for Software Engineers. Conversely, various competencies are complicated and need a lot of time to cultivate in classroom teaching, even though they are equally significant.

Iceberg competency model highlights the importance of university education. Programs offered through university education system need to emphasize on easy to develop competencies, which are at the pinnacle of the triangle. The base competencies of the iceberg are harder to cultivate. The competence modeling findings enlighten university program makers regarding foundation knowledge and skills. This assists the curriculum designers to validate what programs need to be covered in the set of courses to meet the requirements of industry.

Learning of new standards and processes (Adams, 2002) and development of competencies is an inimical component of IT professionals' future concern to stay abreast of the latest developments in the field. Also necessary is to learn futuristic project management and related knowledge (Taff et al., 1991) to aid in smooth transition from a software developer to the project leadership or project management role. This study highlights occupational career paths and the areas requiring development of competencies for software professionals in accordance with the hierarchy levels were identified. Future developments in the IT sector will expose the development path for entry level to senior software professionals.

\section{CONCLUSION AND SCOPE OF FUTURE RESEARCH}

The current research proposes an occupational career and the competence levels associated with the occupational profiles recognized for the firms subject to this study, on the basis of the perspective of software engineers. The occupational career is founded commencing from seven successive profiles, providing solid form to various levels of technical competency. The universal significance of Software Design and Software Engineering Management is replicated in the top levels of competence needed for the diverse occupational profiles. Conversely, Software Maintenance and Software Construction are rated 
very low by software engineers. The occupational profile, "C", correspond to top competence levels in all technical competencies. The pyramidal structure for occupational careers, acknowledging the sole occupational path starting from Junior Programmer to IT Director, is prevalent in the companies even today. Technical competence is maximized in a resolute occupational profile depicted through "C".

From now onwards, other competencies which are not archetypal of Software Engineering achieve significance and inspire occupational progress towards higher levels. On one hand, contentious issues of these kinds of occupational structures, and in contrast, the lack of technical competence in levels higher up in the hierarchy, the breakdown of communication between enhancement of technical competence and occupational growth, are applicable even in modern era, regardless of novel programs that attempt to describe a connection between occupational growth and development in the career. It can be substantiated by the organizational cultures and behavioral inertia of the persons, successors of years of convention of pyramidal professional structures. As far as future research is concerned, description of competence levels for non-technical competencies or generic competencies which are applicable to variety of professions is proposed. This will lead to a framework in which the organizations can set up competence attributes for the profiles. Thus, they can produce an assessment system permitting the recognition of strengths and weaknesses of the of their employees competencies in comparison to well-known standards.

From the perspective of IT sector, this article provides a strong basis for the development of competencies, particularly software quality, software engineering process, software testing, software configuration management, software engineering management, and software maintenance. The competency management framework finally flanks all approaches and makes recommendations which competencies should be developed by which software professional, when, and how.

This implies that the business processes of the software development team require its software professionals to learn new technologies and languages. For this, the software firms initiate collaborations with Microsoft, ORACLE, Novell and other corporations to train their software professionals on future technologies. Thus, one can see that these firms have built-in system features that pre-empt the IT professionals in their field to develop these futuristic-orientation competencies. Hence, the above are the key competency areas for IT professionals and a typical example of 21 st century software engineers. These key activities are summarized as the core competence areas of these organizations. One can thereby utilize this knowledge to develop frames for understanding individual competency levels on each of the above dimensions. Thus, the key competence areas of the software professionals have been established that enable its HR to align their competences around these core activities of quality concern, problem resolution, team work, customer service and future readiness.

From the perspective of IT sector, this article provides a strong basis for the development of competencies, particularly software quality, software engineering process, software testing, software configuration management, software engineering management, and software maintenance. The competency management framework finally flanks all approaches and makes recommendations which competencies should be developed by which software professional, when, and how.

This implies that the business processes of the software development team require its software professionals to learn new technologies and languages. For this, the software firms initiate collaborations with Microsoft, ORACLE, Novell and other corporations to train their software professionals on future technologies. Thus, one can see that these firms have built-in system features that pre-empt the IT professionals in their field to develop these futuristic-orientation competencies. Hence, the above are the key competency areas for IT professionals and a typical example of 21 st century software engineers. These key activities are summarized as the core competence areas of these organizations. One can thereby utilize this knowledge to develop frames for understanding individual competency levels on each of the above dimensions. Thus, the key competence areas of the software professionals have been established that enable its HR to align their competences around these core activities of quality concern, problem resolution, team work, customer service and future readiness. 


\section{REFERENCES}

Abran, A., Bourque, P., Dupuis, R., \& Moore, J. W. (2004). SWEBOK. Guide to the Software Engineering Body of Knowledge. IEEE Computer Society.

Acuña, S. T., \& Juristo, N. (2004). Assigning people to roles in software projects. Software, Practice \& Experience, 34(7), 675-696. doi:10.1002/spe.586

Adams, L. (2002). Training to go. Quality, 41(8), 24-26.

Alhassan, J. K., Abba, E., Misra, S., Ahuja, R., Damasevicius, R., \& Maskeliunas, R. (2020). A Framework for Cyber Ethics and Professional Responsibility in Computing. In Advances in Electrical and Computer Technologies (pp. 299-307). Springer. doi:10.1007/978-981-15-5558-9_28

Ashenhurst, R. L. (1972). Curriculum recommendations for graduate professional programs in information systems. Communications of the ACM, 15(5), 364-398. doi:10.1145/355602.361320

Ashworth, P. D., \& Saxton, J. (1990). On Competence. Journal of Further and Higher Education, 14(2), 3-25. doi:10.1080/0309877900140201

Barney, J. B. (1991). Firm resources and sustained competitive advantage. Journal of Management, 17(1), 99-120. doi:10.1177/014920639101700108

Bassellier, G., Reich, B. H., \& Benbasat, I. (2001). IT Competence of Business Managers: A Definition and Research Model. Journal of Management Information Systems, 17(4), 159-182. doi:10.1080/07421222.2001.11045660

Becker, B., \& Gerhart, B. (1996). The impact of human resource management on organizational performance: Progress and prospects. Academy of Management Journal, 39, 779-801.

Bloom, B. S. (1956). Taxonomy of Educational Objectives: The Classification of Educational Goals. Susan Fauer Company.

Boehm, B. (1981). Software Engineering Economics. Prentice-Hall.

Boehm, B., Horowitz, E., Madachy, R., Reifer, D., Clark, B. K., \& Steece, B. (2000). Software Cost Estimation with COCOMO II. Prentice Hall.

Bourque, P., Buglione, L., Abran, A., \& April, A. (2004). Bloom's Taxonomy Levels for Three Software Engineer Profiles. Proceedings of the Eleventh Annual International Workshop on Software Technology and Engineering Practice (STEP'04).

Boyatzis, R. (1982). The Competent Manager: A Model for Effective Performance. John Wiley and Sons.

Boyatzis, R. (1996). Competencies Can Be Developed But Not in the Way We Thought. Capability, 2(2), $25-41$.

Callahan, D., \& Pedigo, B. (2002). Educating Experienced IT Professionals by Addressing Industry's Needs. IEEE Software, 19(5), 57-62. doi:10.1109/MS.2002.1032855

Cano, C., Fernández-Sanz, L., \& Misra, S. (2013). Featuring CIO: Roles, Skills and Soft Skills. International Journal of Human Capital and Information Technology Professionals, 4(1), 22-33. doi:10.4018/jhcitp.2013010103

Chesebrough, P. H., \& Davis, G. B. (1983). Planning a career path in information systems. Journal of Systems Management, 34(1), 6-13.

Chouhan, V. S., \& Srivastava, S. (2013). Competency Mapping Model for HR Professionals in India. [IJHRMR]. International Journal of Human Resource Management and Research, 3(1), 113-118. http://www.tjprc.org/ publishpapers/2-34-1362976847-12.Competency.full.pdf

Chouhan, V. S., \& Srivastava, S. (2014). Understanding Competencies and Competency Modeling-A literature survey. IOSR Journal of Business and Management, 16(1), 14-22. doi:10.9790/487X-16111422

Chouhan, V. S., \& Srivastava, S. (2015). HR Competency Modeling: An Empirical Study in Indian IT Sector. International Journal of Human Resource Management, 4(4), 1-26. https://archive.org/stream/HRCompetencyMod elingAnEmpiricalStudyInIndianItSector/\%E2\%80\%9CHR\%20Competency\%20Modeling\%20An\%20Empirical\%20 Study\%20in\%20Indian\%20it\%20Sector\%E2\%80\%9D_djvu.txt 
Cockerill, T., Hunt, J., \& Schroder, H. (1995). Managerial Competencies: Fact or Fiction? Business Strategy Review, 6(3), 1-12. doi:10.1111/j.1467-8616.1995.tb00095.x

Constantine, L. (2001). Peopleware Papers: The Notes on the Human Side of Software. Prentice-Hall.

Curtis, B., Hefley, W.E., \& Miller, S.A. (2001). People Capability Maturity Model (P-CMM®) Version 2.0. CMU/ SEI-2001-MM-01.

Dalton, M. (1997). Are Competency Models a Waste? Training \& Development, 10(51), 46-49.

Dasari, S. R. (2008). The Greatest HR Concerns. Retrieved on September 12, 2008 from www.123oye.com

Davis, G. B. (1997). IS ‘97 Model Curriculum and Guidelines for Undergraduate Degree Programs in Information Systems. ACM.

Gabryk, W., \& Naidoo, R. (2020). A Case of Information Technology Value Competency Left Behind? A Scoping Review. In 2020 IEEE International IOT, Electronics and Mechatronics Conference (IEMTRONICS). IEEE.

Gorgone, J., Davis, G. B., Valacich, J. S., Topi H., \& Feinstein D. L. (2003). IS 2002 Model Curriculum and Guidelines for Undergraduate Degree Programs in Information Systems. The DATA BASE for Advances in Information Systems, 34(1).

Gorgone, J. T., Gray, P., Feinstein, D. L., Kasper, G. M., Luftman, J., Stohr, E. A., Valacich, J. S., \& Wigand, R. (2000). MSIS 2000: Model curriculum and guidelines for graduate degree programs in information systems. Communications of the Association for Information Systems, 3, 1-51. doi:10.17705/1CAIS.00301

Gorgone, J. T., Gray, P., Stohr, E. A., Valacich, J. S., \& Wigand, R. T. (2006). MSIS 2006: Model Curriculum and Guidelines for Graduate Degree Programs in Information Systems. Communications of the AIS, 17(17), 1-58. doi:10.1145/1138403.1138448

Guest, D. (2001). Voices from the boardroom. Chartered Institute of Personnel and Development.

Harvard Management Update. (1999). Managing the Labour Shortage. Finding and Keeping - Good Young Employees, 2(4).

Humphrey, W. S. (1998). Managing Technical People: Innovation, Teamwork and the Software Process. AddisonWesley.

Impagliazzo, J., Sabin, M., Alrumaih, H., \& Viola, B. (2016). An information technology competency model and curriculum. In 2016 IEEE Global Engineering Education Conference (EDUCON) (pp. 892-895). IEEE. doi:10.1109/ EDUCON.2016.7474657

Kitchenham, B., Budgen, D., Brereton, P., \& Woodall, P. (2005). An investigation of software engineering curricula. Journal of Systems and Software, 74(3), 325-335. doi:10.1016/j.jss.2004.03.016

Kovacs, P. J., Caputo, D., Turchek, J., \& Davis, G. A. (2006). A survey to define the skill sets of selected information technology professionals. Issues in Information Systems Journal, 7(1), 242-246.

Lanes, W. J. (2001). What is Engineering Management? IEEE Transactions on Engineering Management, 48(1), 107-110. doi:10.1109/17.913170

Lee, P. (2001). Technopreneurial Inclinations and Career Management Strategy among Information Technology Professionals. Proceedings of the 34th Hawaii International Conference on System Sciences. doi:10.1109/ HICSS.2001.927182

Leidig, P. M., Salmela, H., Anderson, G., Babb, J., Gardner, L. A., Nunamaker Jr, J. F., \& de Villiers, C. (2020). ACM/AIS IS2020: Updating the IS Model Curriculum. Academic Press.

Lethbridge, T. C. (2000). What Knowledge Is Important to a Software Professional? Computer, 33(5), 44-50. doi:10.1109/2.841783

Lunt, B. M., Ekstrom, J. J., Gorka, S., Hislop, G., Kamali, R., Lawson, E., LeBlanc, R., Miller, J., \& Reichgelt, H. (2008). Curriculum Guidelines for Undergraduate Degree Programs in Information Technology. Technical Report. ACM. 
Marcolin, B. L., Compeau, D. R., Munro, M. C., \& Huff, S. L. (2000). Assessing User Competence: Conceptualization and Measurement. Information Systems Research, 11(1), 37-60. doi:10.1287/isre.11.1.37.11782

McConnell, S. (2003). Professional Software Development. Addison-Wesley.

McMurtrey, M. E., Downey, J. P., Zeltmann, S. M., \& Friedman, W. H. (2008). Critical skill sets of entry level IT professionals: An empirical examination of perceptions from field personnel. Journal of Information Technology Education, 7, 101-120. doi:10.28945/181

Misic, M. M., \& Graf, D. K. (2004). Systems analyst activities and skills in the new millennium. Journal of Systems and Software, 71(1-2), 31-36. doi:10.1016/S0164-1212(02)00124-3

Nunamaker, J. F. Jr, Couger, J. D., \& Davis, G. B. (1982). Information systems curriculum recommendations for the 80s: Undergraduate and graduate programs. Communications of the ACM, 25(11), 781-805. doi: $10.1145 / 358690.358698$

Pressman, R. (2005). Software Engineering: A Practitioner's Approach. McGraw Hill.

Report, I. S. (2014). The India Skills Report 2014. Retrieved on 13 May, 2019, from https://wheebox.com/wheebox/ resources/IndiaSkillsReport.pdf

Sabin, M., Alrumaih, H., Impagliazzo, J., Lunt, B., \& Zhang, M. (2015). Designing an Information Technology Curriculum Framework to Prepare Successful Graduates in 2025. In Proceedings of the 2015 conference on Innovation \& technology in computer science education (ITiCSE'15). ACM.

Sackman, H., Erikson, W. J., \& Grant, E. E. (1968). Exploratory Studies comparing online and offline programming performance. Communications of the ACM, 11(1), 3-11. doi:10.1145/362851.362858

Sukhoo, A., Barnard, A., Eloff, M. M., Van der Poll, J. A., \& Motah, M. (2005). Accommodating soft skills in software project management. Issues in Informing Science and Information Technology, 2, 691-704. doi:10.28945/860

Taff, L. M., Borchering, J. W., \& Hudgins, W. R. J. (1991). Estimeetings: Development estimates and a front-end process for a large project. IEEE Transactions on Software Engineering, 17(8), 839-850. doi:10.1109/32.83918

Tomayko, J., \& Hazzan, O. (2004). Human aspects of Software Engineerng. Charles River Media.

Topi, H., Karsten, H., Brown, S. A., Alvaro, J., Donnellan, B., Shen, J., \& Thouin, M. F. (2017). MSIS 2016 global competency model for graduate degree programs in information systems. Communications of the Association for Information Systems, 40(18), MSIS-i, MSIS-107. doi:10.17705/1CAIS.04018

Topi, H., Valacich, J. S., Wright, R. T., Kaiser, K., Nunamaker, J., Sipior, J. C., \& de Vreede, G. J. (2010). IS 2010: Curriculum Guidelines for Undergraduate Degree Programs in Information Systems. Communications of the Association for Information Systems, 26(18). Advance online publication. doi:10.17705/1CAIS.02618

United States Department of Labor. (2012). Defining a Quality Pre-Apprenticeship Program and Related Tools and Resources. Employment and Training Administration. Retrieved from https://wdr.doleta.gov/directives/corr_doc. $\mathrm{cfm} ? \mathrm{DOCN}=5842$

Vakola, M., Soderquist, K. E., \& Prastacos, G. P. (2007). Competency Management in Support of Organisational Change. International Journal of Manpower, 28(3/4), 260-275. doi:10.1108/01437720710755245

van Solingen, R., Berghout, E., Kusters, R., \& Trienekens, J. (2000). From process improvement to people improvement: Enabling learning in software development. Information and Software Technology, 42(14), 965-971. doi:10.1016/S0950-5849(00)00148-8

Von Bertalanffy, L. (1968). General systems theory. George Braziller.

Wu, J. H., Chen, Y. C., \& Chang, C. (2007). Critical IS professional activities and skills/knowledge: A perspective of IS managers. Computers in Human Behavior, 23(6), 2945-2965. doi:10.1016/j.chb.2006.08.008

Yoon, C. Y. (2009). Measures of perceived end-user computing competency in an organizational computing environment. Knowledge-Based Systems, 22(6), 471-476. doi:10.1016/j.knosys.2009.06.006 
International Journal of Human Capital and Information Technology Professionals Volume $13 \cdot$ Issue 1

Vikram Singh Chouhan is PhD, MBA, BE with 15 years of teaching experience. He is currently working as Assistant Professor in the Department of Humanities \& Social Sciences at Jaypee University of Engineering and Technology, Guna. He writes and presents widely on issues of Human Resource Management, Organizational Behavior, Employee Training and Development. 